\title{
ANALISIS PENDAPATAN ASLI DAERAH DAN BELANJA PEMBANGUNAN TERHADAP PERTUMBUHAN EKONOMI DI KABUPATEN/KOTA JAWA TIMUR
}

\author{
ANALYSIS OF ORIGINAL REGIONAL INCOME AND CONSTRUCTION \\ EXPENSE ON ECONOMIC GROWTHIN DISTRICT AND JAWA TIMUR CITY
}

\author{
Muhammad Yasin \\ Universitas Teknologi Surabaya \\ muhammadyasin261092@gmail.com
}

\begin{abstract}
Economic growth is a change in the economic process in a country in a sustainable direction for the better in a certain period. Economic growth can also be interpreted as a process of increasing the production capacity of an economy that is realized in the form of an increase in national income. PAD-Free Variables (X1) Measured using: (1) Taxes, (2) Non-taxation, Development Expenditures (X2) Measured using: (1 ) Development, (2) Growth. Economic Growth Variable (Y) Measured using: (1) Efficiency ratio, (2) Effectiveness Ratio, (3) Independence ratio, (4) Ratio of economic growth activity.This means that if the income of the region will also cause an increase in economic growth achievements. which is very flexible in terms of utilization causes the regions to be more flexible in planning the allocation of expenditure budgets for development activities in accordance with their economic agenda which includes the development of basic facilities and infrastructure that play a role in supporting optimal economic growth.
\end{abstract}

Keywords: PAD, Development Expenditure, Economic Growth

\begin{abstract}
ABSTRAK
Pertumbuhan ekonomi adalah perubahan proses perekonomian dalam negara secara berkesinambungan menuju lebih baik dalam preode tertentu. Pertumbuhan ekonomi dapat diartikan juga sebagai proses kenaikan kapasitas produksi suatu perekonomian yang diwujudkan dalam bentuk kenaikan pendapatan nasional.Variabel Bebas PAD (X1) Diukur menggunakan : (1) Pajak, (2) Non pajak, Belanja pembangunan (X2) Diukur menggunakan : (1) Pengembangan, (2) Pertumbuhan. Variabel Pertumbuhan Ekonomi (Y) Diukur menggunakan : (1) Rasio efisiensi, (2) Rasio Efektivitas, (3) Rasio kemandirian, (4) Rasio aktivitas.pertumbuhan ekonomi dengan Hal ini bermakna bahwa apabila pendapatan daerah tersebut maka akan menyebabkan peningkatan pula pada capaian pertumbuhan ekonomi. yang sangat fleksibel dari segi pemanfaatannya menyebabkan daerah lebih leluasa dalam merencanakan alokasi anggaran belanja untuk kegiatan pembangunan sesuai dengan agenda ekonominya yang antara lain berupa pembangunan sarana dan prasarana dasar yang berperan dalam menunjang pertumbuhan ekonomi yang optimal.
\end{abstract}

Kata Kunci : PAD, Belanja Pembangunan, Pertumbuhan Ekonomi 


\section{PENDAHULUAN}

Pertumbuhan ekonomi adalah proses perubahan kondisi perekonomian suatu negara secara berkesinambungan menuju keadaan yang lebih baik selama periode tertentu. Pertumbuhan ekonomi dapat diartikan juga sebagai proses kenaikan kapasitas produksi suatu perekonomian yang diwujudkan dalam bentuk kenaikan pendapatan nasional. Pertumbuhan ekonomi selama ini sangat ditentukan oleh faktor belanja pembangunan daerah fasilitas-fasilta publik dan pembangunan infrastrukut meningkatkan pelayanan kulitas msyarakat kepada daya tarik bagi semua investor.

Dalam era desentralisasi fiskal sekarang ini, diharapkan adanya peningkatanpelayanan di beberapa sektor palingutama sektor publik, dengan adanya peningkatan dalamlayanan di sektor publik dapat menambah daya tarik bagi investor untuk menanamkan modalnya di daerah. Oleh karana itu, pergeseran komposisi belanjamerupakan upaya logis yang dilakukan Pemda dalam rangka meningkatkan tingkat kepercayaan publik yang dapat dilakukan dengan meningkatkan investasi modal dalam bentuk aset tetap, yakni peralatan, bangunan, infrastruktur dan harta tetap lainnya (Irman \& Purwati, 2020).

Analisis keuangan rasio pada APBD dapat dilakukan dengan perbandingan hasil yang dicapai dalam satu periode dibandingkan dengan periode sebelumnya sehingga diketahui dapat kecenderungan bagaimana yang terjadi, atau dapat pula dengan dilakukan cara rasio perbandingan keuangan yang dimiliki suatu pemerintah daerah tertentu rasio keuangan daerah lain yang terdekat ataupun potensi daerahnya relatif sama untuk dilihat bagaimana posisi rasio keuangan pemerintah daerah tersebut terhadap pemerintah daerah lainnya. Dengan adanya Pendapatan Asli Daerah (PAD) bisa tahu keuangan setiap kabupaten atau kota oleh karena itu kinerja keuangan bisa ditingkatkan melalui peningkatan pelayanan dari setiap kabupaten atau kota dan ditunjang oleh infrastruktur yang memadahi agar Pendapatan Asli Daerah (PAD) meningkat dan pelayanan publik bisa maksimal.

Dalam mengelolah keuangan dibutuhkan suatu ilmu yang mempelajari pengelolahan keuangan yang baik dan benar. Ilmu tersebut sering disebut dengan manajemen keuangan. Manajemen Keuangan sering digunakan dan dibutuhkan dalam pengelolahan keuangan disegala bidang, tak dikecualikan pengelolahan keuangan daerah. Peraturan Pemerintah No. 105 Tahun 2000, keuangan daerah menyatakan: Semua hak dan kewajiban daerah dalam rangka penyelenggaraan pemerintah daerah yang dapat dinilai dengan uang termasuk di dalamnya segala bentuk kekayaan yang berhubungan dengan hak dan kewajiban daerah tersebut, dalam kerangka pendapatan anggaran dan belanja daerah (APBD).

Manajemen keuangan daerah merupakan proses perencanaan, pengorganisasian, kepemimpinan dan pengendalian terhadap semua hak dan kewajiban daerah penyelenggaraan pemerintah yang ada yang segalanya dinilai dengan uang, dan masuk dalam kekayaan yang berhubungan dengan hak serta kewajiban daerah dalam rangka anggaran pendapatan dan belanja daerah (Syukri \& Hinaya, 2019).

Pembangunan Ekonomi adalah merupakan salah satu upaya dalam rangka mendukung pelaksanaan salah satu prioritas yang tercantum 
dalam Prioritas Pembangunan Nasional, yaitu mempercepat pemulihan ekonomi dan memperkuat landasan pembangunan ekonomi berkelanjutan dan berkeadilan berdasarkan sistem kerakyatan. Penetapan prioritas tersebut mendasarkan pada masalah dan tantangan yang dihadapi serta arah kebijakan dalam pembangunan ekonomi, baik pembangunan jangka pendek maupun jangka menengah.

Secara umum pertumbuhan ekonomi dapat diartikan perkembangan kegiatan dalam perekonomian yang menyebabkan barang dan jasa yang diproduksi dalam masyarakat bertambah dan kemakmuran masyarakat meningkat. Pertumbuhan ekonomi dapat juga diartikan sebagai kenaikan Gross Domestic Product (GDP) atau Gross National Product (GNP) tanpa memandang apakah kenaikan itu lebih besar atau lebih kecil dari tingkat pertumbuhan penduduk atau apakah perubahan struktur ekonomi terjadi atau tidak (Irman \& Purwati, 2020). Dari beberapa definisi diatas dapat disimpulkan bahwa pertumbuhan ekonomi merupakan kemampuan suatu negara dalam menyediakan kebutuhan akan barang dan jasa kepada masyarakat dalam jumlah yang banyak sehingga memungkinkan untuk kenaikan standar hidup yang mana berdampak pula bagi penurunan tingkat pengangguran dalam jangka panjang.

Ada tiga faktor atau komponen utama pertumbuhan ekonomi, yaitu akumulasi modal, pertumbuhan penduduk, dan hal-hal yang berhubungan dengan kenaikan jumlah angkatan kerja yang dianggap secara positif merangsang pertumbuhan ekonomi (Rahman et al., 2019).

Pendapatan asli daerah adalah penerimaan yang diperoleh dari sektor pajak daerah, retribusi daerah, hasil perusahaan milik daerah, hasilpengeloalaan kekayaan daerah yang dipisahkan, dan lain-lain pendapatan asli daerah yang sah (Putra \& Ulupui, 2019). Optimalisasi dalam penerimaan PAD hendaknya di dukung dengan upaya pemerintah daerah meningkatkan kualitas layanan publik. Eksploitasi PAD yang berlebihan justru akan semakin membebani masyarakat, menjadi disinsentif bagi daerah dan mengancam perekonomian secara makro.

Tidak efektifnya berbagai peraturan yang dilakukan pemerintah bisa jadi menunjukkan tidak adanya relasi positif antara berbagai pungutan baru itu dengan kesungguhan pemerintah daerah dalam meningkatkan mutu layanan publik. Perlu adanya kebijakan peraturan daerah yang tepat untuk melakukan pungutan yang akan dilakukan oleh pemerintah daerah. PAD sebagai sumber utama penghasilan bagi daerah. PAD terbagi menjadi tiga kategori, yaitu pajak daerah, denda dan pungutan, serta penghasilan perusahaan daerah. Ketiga kategori tersebuat tercantum dalam UU No.33 Tahun 2004 pasal 6 ayat 1 yang menyatakan bahwa sumber PAD terdiri dari pajak daerah, retribusi daerah, hasil pengelolaan kekayaan daerah yang dipisahkan, dan lain-lain PAD yang sah.

Pajak daerah yang menjadi sorotan publik yang dipandang sebagai jenis penghasilan utama yang diperoleh daerah. Pada umumnya, pemerintah pusatlah yang akan menentukan pajak yang dapat dipungut oleh pemerintah daerah. Kategori kedua dari Pendapatan Asli Daerah adalah pungutan biaya, denda, dan lisensi. Sumber pendapatan ini terikat dengan seseorang untuk membayar pelayanan tertentu yang dipergunakannya. Pemerintah daerah memungut biaya atas pelayanan dan lisensi yang sudah disediakan. dari Pendapatan Asli daerah penghasilan 
dari utilitas dan perusahaaan daerah. Perusahaan daerah mendapatkan penghasilan melalui pembebanan biaya atas barang maupun jasa yang ditawarkannya. Pada prinsipnya pembebanan wilayah ini memainkan peran fiskal dan regulasi berupa Pengumpulan pendapatan dan mengatur permintaan jasa dengan meminamalisasi pelanggaran yang sering terjadi dalam pelayanan publik yang bebas biaya. Jadi Pendapatan Asli Daerah adalah Pemerintah daerah melalui upayanya memenuhi kewajiban daerah salah satu tujuannya yaitu meningkatkan perekononomian yang diharapkan secara langsung akan berdampak meningkatkan kualitas hidup masyarakatnya. Dalam rangka memenuhi tujuan tersebut pemerintah diharapkan dapat mempunyai sistem keuangan sendiri baik dari sisi pendapatan maupun pengeluaran sehingga tidak bergantung pada pemerintah pusat.

Belanja Pembangunan adalah pengeluaran-pengeluaran pemerintah yang non konsumtif, berbentuk investasi (proyek-proyek) baik berbentuk proyek fisik maupun non fisik" (Triastuti \& Pramono, 2016). Belanja Pembangunan sebagai pengeluaran pemerintah yang bersifat investasi, dan diajukan untuk melaksanakan tugas-tugas pemerintah sebagai salah satu pelaku pembangunan.

Belanja Pembangunan tersebut meliputi belanja pembangunan dalam bentuk rupiah dan belanja pembangunan dalam bentuk bantuan proyek yang dibiayai dari pijaman atau hibah luar negeri. Belanja pembangunan dalam bentuk rupiah bersumber dari tabungan pemerintah dan bantuan program yang digunakan untuk membiayai belanja-belanja sektoral melalui departemen atau lembaga non departemen dan dialokasikan pula untuk membiayai proyek-proyek.

Dari pengertian tersebut, maka dapat disimpulkan bahwa belanja pembangunan adalah semua pengeluaran pemerintah daerah pada satu periode anggaran yang berupa arus aktiva keluar guna melaksanakan kewajiban, wewenang, dan tanggung jawab kepada masyarakat dan pemerintah pusat (Eka \& Martini, 2015).

Beberapa penelitian terdahulu yang juga mengkaji hubungan pendapatan asli daerah dan belanja pembangunan terhadap pertumbuhan ekonomi di antaranya Adi (2016), namun di antara penelitian terdahulu tersebut hanya fokus terhadap hubungan belanja terhadap pendapatan daerahnya saja, masih minim sekali penelitian yang mengaitkannya dengan pertumbuhan ekonomi.

\section{METODE PENELITIAN}

Pendekatan ini menggunakan pendekatan kualitatif dan kuantitatif. Pendekatan kualitatif' adalah penelitian tentang riset yang bersifat deskriptif dan cenderung menggunakan analisis. Proses dan makna (perspektif subjek) lebih ditonjolkan dalam penelitian kualitatif. Landasan teori dimanfaatkan sebagai pemandu agar fokus penelitian sesuai dengan fakta di lapangan.

Sampel penelitian ditentukan dengan Purposive random sampling adalah metode penentuan sampel berdasarkan kriteria tertentu guna memenuhi syarat sampel yang baik. Kriteria tersebut yakni: 1) sampel adalah 29 Kabupaten dan 9 Kota di Provinsi Jawa Timur, 2) APBD Kabupaten dan Kota

Sebagian populasi yang karakteristiknya hendak diselidiki dan dianggap mewakili keseluruhan 
populasi. Batas kesalahan yang ditolelir ini untuk setiap populasi tidak sama, Karena kinerja di setiap Daerah Provinsi Jawa Timur berbeda sebanyak29 kabupaten dan 9 kota, dimana seluruh populasi yang ada disaring berdasarkan data keuangan yang telah ditentukan, karna untuk memahami bagaimana struktur APBD mempengaruhi kinerja keuangan daerah dan pertumbuhan ekonomi. Teknik pengumpulan data penelitian ini melalui beberapa prosedur sebagai berikut:

1. Studi perpustakaan, yaitu mempelajari literatur-literatur terutama mengenai PAD dan Belanja Rutin terhadap kinerja keuangan daerah sehingga dapat membahas atau memecahkan apa yang telah dikemukakan sebelumnya.

2. Studi lapangan, dilakukan ini adalah melalui Bapeda Provinsi Jawa Timur, studi lapangan bertujuan untuk mengetahui pertumbuhan ekonomi Daerah Provinsi Jawa Timur yang sesuai dengan variable yang diteliti.

Bila dilihat dari sumber datanya, maka pengambilan data dapat menggunakan sumber primer, dan sumber sekunder. Sumber primer adalah sumber data yang langsung memberikan data kepada pengumpul data, dan sumber sekunder merupakan sumber yang tidak langsung memberikan data kepada pengumpul data, misalnya lewat orang lain atau lewat dokumen

Data APBD di peroleh dari BAPEDA Provinsi Jawa Timur merupakan teknik pengumpulan data yang efisien bila peneliti tahu dengan pasti variabel yang akan diukur dan tahu apa yang bisa diharapkan dari data APBD. Selain itu, Dalam penelitian kuantitatif, peneliti akan menggunakan instrumen untuk pengumpulan data, sedangkan dalam penelitian kualitatifnaturalistik peneliti akan lebih banyak menjadi instrumen, karena dalam penelitian kualitatif peneliti merupakan Key instrumen. Karena instrumen penelitian akan digunakan untuk melakukan pengukuran dengan tujuan menghasilkan data kuantitatif dan kualitatif yang akurat, maka setiap struktur APBD harus mempunyai data yang akurat. Bermacam-macam struktur APBD yang di analisis yaitu berbagai struktur APBD yang dapat digunakan untuk penelitian.

Analisa data dalam penelitian ini menggunakan aplikasi program PLS (Partial Least Square) versi 3.0 M3 PLS (Partial Least Square) dikembangkan pertama kali oleh wold sebagai metode umum untuk mengestimasi path model yang menggunakan konstruk laten dengan mutipe indikator. PLS (Partial Least Square) merupakan factor indeterminacy metode analisis yang powerful oleh karena tidak mengasumsikan data harus dengan pengukuran skala tertentu, jumlah sampel kecil. PLS (Partial Least Square) dapat juga digunakan untuk konfirmasi teori.

\section{HASIL DAN PEMBAHASAN \\ Uji Discriminant Validity.}

Tabel 1 Average Variance Extracted

\begin{tabular}{ll}
\hline & $\begin{array}{l}\text { Average } \\
\text { Extracted (AVE) }\end{array}$ \\
\hline PAD & 1.000 \\
\hline $\begin{array}{l}\text { Belanja } \\
\text { Pembangunan }\end{array}$ & 1.000 \\
\hline $\begin{array}{l}\text { Pertumbuhan } \\
\text { ekonomi }\end{array}$ & 1.000 \\
Sumber : Data Olahan (2019)
\end{tabular}

Tabel diatas dapat disimpulakan bahwa akar AVE konstruk PAD sebesar 1.000 ( $\sqrt{ } 1.000)$, AVE konstruk Belanja 
Pembangunan sebesar $1.000(\sqrt{ } 1.000)$, AVE konstruk Kinerja Keuangan sebesar $1.000(\sqrt{ } 1.000)$ dan AVE konstruk Pertumbuhan Ekonomi . Jadi semua konstruk dalam model yang diestimasi memenuhi kriteria Discriminant Validity.

\section{Uji Statistik}

Untuk membuktikan hipotesis yaitu dengan melihat signifikasi pengaruh antar variable dengan melihat koefisien parameter dan nilai signifikansi t statistic. Pada PLS hal tersebut dilakukan dengan melihat Algorithm Boostrapping report, berikut hasilnya :

Tabel 2 Path Coefficients (Mean, STDEV, TValues, P-Values)

\begin{tabular}{|c|c|c|c|c|c|c|}
\hline & $\begin{array}{l}\text { Origi } \\
\text { nal } \\
\text { Samp } \\
\text { le }(0)\end{array}$ & $\begin{array}{l}\text { Sam } \\
\text { ple } \\
\text { Mea } \\
\text { n } \\
\text { (M) }\end{array}$ & $\begin{array}{l}\text { Standar } \\
\text { d } \\
\text { Deviati } \\
\text { on } \\
\text { (STDE } \\
\text { V) } \\
\end{array}$ & $\begin{array}{l}\text { T } \\
\text { Statis } \\
\text { tics } \\
(\mid \mathrm{O} / \mathrm{S} \\
\text { TDE } \\
\text { V|) } \\
\end{array}$ & $\begin{array}{l}\text { P } \\
\text { Valu } \\
\text { es }\end{array}$ & $\begin{array}{l}\text { Hipo } \\
\text { tesis }\end{array}$ \\
\hline $\begin{array}{l}\text { PAD -> } \\
\text { Pertumbu } \\
\text { han } \\
\text { Ekonomi }\end{array}$ & 0.115 & $\begin{array}{r}0.36 \\
1\end{array}$ & 0.160 & 2.245 & $\begin{array}{r}0.02 \\
5\end{array}$ & Sig \\
\hline $\begin{array}{l}\text { Belanja } \\
\text { Pembang } \\
\text { unan - } \\
\text { >Pertumb } \\
\text { uhan } \\
\text { Ekonomi }\end{array}$ & 0.105 & $\begin{array}{r}0.10 \\
3\end{array}$ & 0.210 & 2.597 & $\begin{array}{r}0.04 \\
7\end{array}$ & Sig \\
\hline
\end{tabular}

Sumber : Data Olahan (2019)

Path Coefficient menunjukkan tingkat signifikasi dan hubungan antar variabel. Dengan demikian memberikan hasil sebagai berikut:

\section{Terdapat Pengaruh Signifikan PAD terhadap Pertumbuhan Ekonomi}

PAD terhadap Pertumbuhan

Ekonomi daerah di kabupaten dan kota se-jawa timur adalah signifikan dengan t-statistik sebesar $2.245(>1,96)$. Nilai original sample estimate adalah negatif yaitu sebesar 0.115yang menunjukkan bahwa arah hubungan antara PAD terhadap Pertumbuhan Ekonomi daerah adalah positif.

Pendapatan Asli Daerah dapat diartikan sebagai pendapatan yang bersumber dari pungutan-pungutan yang dilaksanakan oleh daerah berdasarkan peraturan-peraturan yang berlaku yang dapat dikenakan kepada setiap orang atau badan usaha baik milik pemerintah maupun swasta karena perolehan jasa yang diberikan oleh pemerintah tersebut. Oleh sebab itu daerah dapat melaksanakan pungutan dalam bentuk penerimaan pajak, retribusi, dan penerimaan lainnya yang sah yang diatur dalam undang-undang (Yasin, 2019).

Peningkatan Pendapatan Asli Daerah (PAD) akan mengakibatkan peningkatan kinerja keuangan pemerintah.Hal ini dapat terjadi pada Kabupaten/Kota di Daerah Provinsi Jawa Timur untuk menekankan hasil PAD yang berasal dari berbagai sumber yang dikelola oleh pemerintah daerah dalam bentuk Penerimaan pajak, retribusi, dan penerimaan lainnya yang sah yang diatur dalam Undang-Undang. Penelitian ini sesuai dengan penelitian Putri (2015) yang juga mengatakan bahwa PAD berpengaruh signifikan terhadap pertumbuhan ekonomi.

\section{Terdapat Pengaruh Signifikan Belanja Pembangunan terhadap Pertumbuhan Ekonomi}

Belanja pembangunan terhadap pertumbuhan ekonomiadalah signifikan dengan t-statistik sebesar $2.759(>1,96)$. Nilai original sample estimate adalah positif yaitu sebesar 0.105 yang menunjukkan bahwa arah hubungan antara belanja pembangunan terhadap pertumbuhan ekonomio adalah positif.

Hubungan positif dan signifikan variabel belanja langsung terhadap pertumbuhan ekonomi menunjukkan bahwa realisasi pengeluaran pemerintah 
daerah melalui belanja langsung berhasil mendongkrak pertumbuhan ekonomi daerah.

Refleksi trend PDRB mendeskripsikan bahwa pertumbuhan ekonomi dipacu oleh tinggi rendahnya barang dan jasa yang dihasilkan, dimana untuk memaksimalkan produktivitas barang dan jasa diperlukan anggaran belanja langsung yang besar. Hasil penelitian Rizky et al., (2016) yang membuktikan bahwa belanja modal bepengaruh positif signifikan pada pertumbuhan ekonomi. ini membuktikan bahwa tingginya realisasi belanja langsung merupakan indikator penting dalam menunjang pertumbuhan ekonomi

\section{PENUTUP}

\section{Kesimpulan}

Berdasarkan hasil penelitian ditemukan bahwa:

1. PAD terhadap Pertumbuhan Ekonomi daerah di kabupaten dan kota se-jawa timur adalah signifikan dengan $\mathrm{t}$-statistik sebesar 2.245 (>1,96). Nilai original sample estimate adalah negatif yaitu sebesar 0.115yang menunjukkan bahwa arah hubungan antara PAD terhadap Pertumbuhan Ekonomi daerahadalah positif.

2. Belanja pembangunan terhadap pertumbuhan ekonomiadalah signifikan dengan t-statistik sebesar 2.759 (>1,96). Nilai original sample estimate adalah positif yaitu sebesar 0.105 yang menunjukkan bahwa arah hubungan antara belanja pembangunan terhadap pertumbuhan ekonomio adalah positif.

\section{Saran}

Saran yang dapat diberikan peneliti berdasarkan hasil penelitian ini adalah sebagai berikut :

1. Diharapkan Pemerintah Daerah di setiap Kabupaten dan Kota di Provinsi Jawa Timur sebaiknya lebih memperhatikan bagaimana meningkatkan kinerja keuangan Daerah sehingga dapat diharapkan bisa meningkatkan Pendapatan Asli Daerah (PAD) untuk mengalokasi anggaran ke Belanja Rutin supaya pertumbuhan ekonomi setiap kabupaten dan kota di Provinsi Jawa Timur bisa sejahtera.

2. Kinerja Keuangan yang ada disetiap Kabupaten dan Kota di Jawa Timur untuk tetap dipantau oleh Kepala Daerah supaya bisa di maksimalkan keuangan tersebut dalam Pertumbuhan Ekonomi di setiap Kabupaten dan Kota di Provinsi Jawa Timur

\section{DAFTAR PUSTAKA}

Adi, P., H. (2016). Hubungan antara pertumbuhan ekonomi daerah, belanja pembangunan dan pendapatan asli daerah. Simposium Nasional Akuntansi IX.

Eka, S., I., P., \& Martini, D., N. P. (2015). Pengaruh Tingkat Pendidikan, Struktur Ekonomi dan Belanja Pembangunan terhadap kemiskinan Provinsi Bali. E-Jurnal Ekonomi Pembangunan Universitas Udayana, 4(2), 44-52

Irman, M., \& Purwati, A. A. (2020). Analysis On The Influence Of Current Ratio, Debt to Equity Ratio and Total Asset Turnover Toward Return On Assets On The Otomotive and Component Company That Has Been Registered In Indonesia Stock 
Exchange Within 20112017. International Journal of Economics Development Research (IJEDR), 1(1), 36-44.

Putra, P. G. M., \& Ulupui, I. G. K. A. (2019). Pendapatan Asli Daerah, Dana Alokasi Umum, Dana Alokasi Khusus, Untuk Meningkatkan Indeks Pembangunan Manusia. EJurnal Akuntansi, 863-877.

Putri, Z. E. (2015). Analisis Pengaruh Pendapatan Asli Daerah (PAD), Dana Alokasi Uumum (DAU) dan Inflasi Terhadap Pertumbuhan Ekonomi di Kabupaten/Kota Propinsi Jawa Tengah. Esensi: Jurnal Bisnis dan Manajemen, 5(2).

Rahman, S., Suwitho, S., Oh, A., \& Purwati, A. A. (2019). Commercialization of HighTech Innovations and Economic Growth in The Worldwide Most Innovative Countries.

Rizky, R. L., Agustin, G., \& Mukhlis, I. (2016). Pengaruh Penanaman Modal Asing, Penanaman Modal Dalam Negeri Dan Belanja Modal Terhadap Pertumbuhan Ekonomi Provinsi Di Indonesia. Jurnal Ekonomi dan Studi Pembangunan, 8(1), 9-16.

Syukri, M., \& Hinaya, H. (2019). Pengaruh Pertumbuhan Ekonomi, Pendapatan Asli Daerah, Dana Alokasi Umum dan Dana Alokasi Khusus terhadap Anggaran Belanja Modal Kabupaten \& Kota Provinsi Sulawesi Selatan. JEMMA| Journal of Economic, Management and Accounting, 2(2), 30-37.
Triastuti, D., \& Pratomo, D. (2016). Pengaruh Pertumbuhan Ekonomi, Belanja Pembangunan/Modal, Dan Tingkat Inflasi Terhadap Penerimaan Pajak Daerah (Studi pada Pemerintah Daerah Kota Bandung Periode 20072014). eProceedings of Management, 3(1).

Yasin, M., 2019. Analysis Of Regional Original Income Levels In Regional Financial Performance On Economic Growth In East Java Province. Archives of Business Research (ABR), 7(10). 